\title{
STANDARD SINE FITTING ALGORITHMS APPLIED TO BLADE TIP TIMING DATA
}

\section{ZASTOSOWANIE STANDARDOWYCH ALGORYTMÓW DOPASOWANIA FUNKCJI SINUS DO DANYCH POMIAROWYCH DRGAŃ LOPATEK}

\author{
Krzysztof Kaźmierczak, Radosław Przysowa
}

Instytut Techniczny Wojsk Lotniczych

e-mail: radoslaw.przysowa@itwl.pl; krzysztof.kazmierczak@itwl.pl

\begin{abstract}
Blade Tip Timing (BTT) is a non-intrusive method to measure blade vibration in turbomachinery. Time of Arrival (TOA) is recorded when a blade is passing a stationary sensor. The measurement data, in form of undersampled (aliased) tip-deflection signal, are difficult to analyze with standard signal processing methods like digital filters or Fourier Transform. Several indirect methods are applied to process TOA sequences, such as reconstruction of aliased spectrum and Least-Squares Fitting to harmonic oscillator model. We used standard sine fitting algorithms provided by IEEESTD-1057 to estimate blade vibration parameters. Blade-tip displacement was simulated in time domain using SDOF model, sampled by stationary sensors and then processed by the sinefit.m toolkit. We evaluated several configurations of different sensor placement, noise level and number of data. Results of the linear sine fitting, performed with the frequency known a priori, were compared with the non-linear ones. Some of non-linear iterations were not convergent. The algorithms and testing results are aimed to be used in analysis of asynchronous blade vibration.
\end{abstract}

Keywords: turbomachinery, blade vibration, tip-timing, sine fitting, least squares, harmonic oscillator

Streszczenie: Metoda dyskretno-fazowa (ang. tip-timing) jest nieinwazyjnym sposobem pomiaru drgań topatek $w$ przepływowych maszynach wirnikowych. Czas przyjścia zapisywany jest w momencie, kiedy topatka mija stacjonarny czujnik. Do analizy danych pomiarowych $w$ formie rzadko próbkowanego sygnatu odksztatcenia wierzchotka (aliasing) wykorzystano standardowe metody dopasowania funkcji sinus dostarczone przez norme IEEE-STD-1057 w celu estymacji parametrów drgań topatek. Przemieszczenia wierzchotków topatki $w$ dziedzinie czasu zasymulowano wykorzystujac model oscylatora o jednym stopniu swobody. Wyniki liniowego dopasowania, wykonanego ze znana a priori częstotliwościa, porównano z wynikami dopasowania nieliniowego. Uzyskane algorytmy i wyniki testowania mają być wykorzystane do analizy drgań asynchronicznych topatek.

Stowa kluczowe: przephywowe maszyny wirnikowe, drgania topatek, metoda dyskretnofazowa, dopasowanie funkcji sinus, metoda najmniejszych kwadratów, oscylator harmoniczny 
Standard Sine Fitting Algorithms Applied to Blade Tip Timing Data

Zastosowanie standardowych algorytmów dopasowania funkcji sinus do danych...

\section{Introduction}

Experimental results are subject to measurement uncertainty and noise. Data fitting to the model with the method of least squares is one of the most common numerical techniques. Fitting of lines and polynomial curves is a well-known procedure, but trigonometric functions are more demanding. However, sine fitting is widely used in engineering, including testing of $\mathrm{AD}$ converters used in audio industry. This work uses algorithms and tools developed as a result of international cooperation [[1], [2], [3]] and are available in the form of IEEE-Std-1057 standard [[4]] and the corresponding MATLAB toolkit (sinefit.m).

Only a few points per the cycle of the sine function can be used to estimate parameters of blade vibration. This is due to the limited number of sensors that can be installed into the casing. Unlike common signals, TOA data are sampled nonuniformly.

\section{Sine fitting algorithms}

As pointed out in 2008 in the IEEE Std 1057 document, there are two main ways to fit the sine function. There are three-parameter or four-parameter least squares fitting algorithms using matrix operations.

Three-parameter algorithm is used by applying the method of least squares in order to fit a sine wave to the registered points when the frequency of the sinusoid is known. Matrix notation of the used solution is based on the following sine wave equation:

$$
x[n]=A_{0} \cos \left(2 \pi f_{0} t_{n}\right)+B_{0} \sin \left(2 \pi f_{0} t_{n}\right)+C_{0}
$$

Assuming that the registered data consists of a sequence of $x[1], x[2], \ldots, x[M]$ samples, respectively stored at time $t_{1}, t_{2}, \ldots, t_{M}$, the algorithm seeks the values of $\mathrm{A}_{0}, \mathrm{~B}_{0}$ and $\mathrm{C}_{0}$, which are minimizing the square sum of the differences represented by the following equation:

$$
\sum_{n=1}^{M}\left[x[n]-A_{0} \cos \left(2 \pi f_{0} t_{n}\right)-B_{0} \sin \left(2 \pi f_{0} t_{n}\right)-C_{0}\right]^{2}
$$

where $\mathrm{f}_{0}$ is a known sine wave frequency value matched with the recorded data.

To come to a solution, the values of $\mathrm{A}_{0}, \mathrm{~B}_{0}$ and $\mathrm{C}_{0}$ must be calculated, which is not a difficult process, notwithstanding the fact that the equation is a linear function. At the beginning, we have to create the following two matrices:

$$
D_{0}=\left[\begin{array}{ccc}
\cos \left(2 \pi f_{0} t_{1}\right) & \sin \left(2 \pi f_{0} t_{1}\right) & 1 \\
\cos \left(2 \pi f_{0} t_{2}\right) & \sin \left(2 \pi f_{0} t_{2}\right) & 1 \\
\vdots & \vdots & \vdots \\
\cos \left(2 \pi f_{0} t_{M}\right) & \sin \left(2 \pi f_{0} t_{M}\right) & 1
\end{array}\right]
$$




$$
x=\left[\begin{array}{c}
x[1] \\
x[2] \\
\vdots \\
x[M]
\end{array}\right]
$$

and assume that:

$$
s_{0}=\left[\begin{array}{l}
A_{0} \\
B_{0} \\
C_{0}
\end{array}\right]
$$

In matrix notation, the sum of square differences from the equation nr. 2 can be represented by the equation:

$$
\left(x-D_{0} s_{0}\right)^{T}\left(x-D_{0} s_{0}\right)
$$

where $\mathrm{T}$ denotes the transpose of the matrix.

Least-squares solution which minimizes the above equation is represented by the equation:

$$
\widehat{s_{0}}=\left(D_{0}^{T} D_{0}\right)^{-1}\left(D_{0}^{T} x\right)
$$

Finally, the obtained vector $\widehat{s_{0}}$ components, can be used to solve the fitted function. In order to determine its amplitude and phase, which can be found in the formula $x[n]=A \cos \left(2 \pi f_{0} t_{n}+\varphi\right)+C$, the following equation should be solved:

$$
\begin{gathered}
A=\sqrt{A_{0}^{2}+B_{0}^{2}} \\
\varphi=-\arctan \left(B_{0}, A_{0}\right)
\end{gathered}
$$

The residuals of the fit and its error can be obtained from equations:

$$
\begin{gathered}
r[n]=x[n]-A_{0} \cos \left(2 \pi f_{0} t_{n}\right)-B_{0} \sin \left(2 \pi f_{0} t_{n}\right)-C_{0} \\
\varepsilon_{r m s}=\sqrt{\frac{1}{M} \sum_{n=1}^{M} r[n]^{2}}
\end{gathered}
$$

Four-parameter fit algorithm is used when we do not know the frequency of the sinusoidal signal. Sine wave equation is similar to that described in three-parameter algorithm, with the only difference that the parameter $\mathrm{f}_{0}$ is unknown. This entails, unfortunately, the consequences of changing the nature of non-linear equations, which also involves the way to solve it. In this case, the iterative method must be applied.

Assuming that the recorded data contains the sequence of samples $\mathrm{x}[1], \mathrm{x}[2], \ldots, \mathrm{x}[\mathrm{M}]$ respectively stored at time $\mathrm{t}_{1}, \mathrm{t}_{2}, \ldots, \mathrm{t}_{\mathrm{M}}$, the algorithm, 
Standard Sine Fitting Algorithms Applied to Blade Tip Timing Data

Zastosowanie standardowych algorytmów dopasowania funkcji sinus do danych...

in iterative process, is looking for $\mathrm{A}_{\mathrm{i}}, \mathrm{B}_{\mathrm{i}}, \mathrm{C}_{\mathrm{i}}$ and $\mathrm{f}_{\mathrm{i}}$ values which are minimizing the square sum of the differences represented by the following equation:

$$
\sum_{n=1}^{M}\left[x[n]-A_{i} \cos \left(2 \pi f_{i} t_{n}\right)-B_{i} \sin \left(2 \pi f_{i} t_{n}\right)-C_{i}\right]^{2}
$$

where " $\mathrm{i} "$ is the number of the next iteration.

Appropriate algorithm, which should be followed to get the solution, is presented below:

a) set the iteration index $\mathrm{i}=0$,

b) make an initial estimation of the recorded data frequency $\mathrm{f}_{0}$. For this task, you can use the DFT (for all or a part of the record), taking the inverse of the average period between zero crossings or taking into account the best result when applied input frequency. A very effective method is to use the fast Fourier interpolation, which were presented in the work of Schoukens and Bilau. This method operates with interpolated formula on DFT coefficients of the recorded data and is often used in applications for testing ADCs,

c) perform preliminary matching using three-parameter fit algorithm to determine $\mathrm{A}_{0}, \mathrm{~B}_{0}$ i $\mathrm{C}_{0}$

d) set $\mathrm{i}=\mathrm{i}+1$ for the next iteration,

e) create matrices presented below:

$$
\begin{aligned}
& x=\left[\begin{array}{c}
x[1] \\
x[2] \\
\vdots \\
x[M]
\end{array}\right] \\
& D_{0}=\left[\begin{array}{ccccc}
\cos \left(2 \pi f_{i} t_{1}\right) & \sin \left(2 \pi f_{i} t_{1}\right) & 1 & -A_{i-1} t_{1} \sin \left(2 \pi f_{i} t_{1}\right) & B_{i-1} t_{1} \sin \left(2 \pi f_{i} t_{1}\right) \\
\cos \left(2 \pi f_{i} t_{2}\right) & \sin \left(2 \pi f_{i} t_{2}\right) & 1 & -A_{i-1} t_{2} \sin \left(2 \pi f_{i} t_{2}\right) & B_{i-1} t_{2} \sin \left(2 \pi f_{i} t_{2}\right) \\
\vdots & \vdots & \vdots & \vdots & \vdots \\
\cos \left(2 \pi f_{i} t_{M}\right) & \sin \left(2 \pi f_{i} t_{M}\right) & 1 & -A_{i-1} t_{M} \sin \left(2 \pi f_{i} t_{M}\right) & B_{i-1} t_{M} \sin \left(2 \pi f_{i} t_{M}\right)
\end{array}\right](14) \\
& x=\left[\begin{array}{c}
A_{i} \\
B_{i} \\
C_{i} \\
\Delta f_{i}
\end{array}\right]
\end{aligned}
$$

f) determine the solution of least squares using the following equation:

$$
\widehat{s_{l}}=\left(D_{i}^{T} D_{i}\right)^{-1}\left(D_{i}^{T} x\right)
$$

g) update frequency estimation using the relationship:

$$
f_{i}=f_{i-1}+\Delta f_{i-1}
$$

for $\mathrm{i}=1$ the value $\Delta f_{i-1}=0$ 
h) determine the amplitude and phase in the equation $x[n]=A \cos \left(2 \pi f_{i} t_{n}+\varphi\right)+C$ using relationships shown below:

$$
\begin{gathered}
A=\sqrt{A_{i}^{2}+B_{i}^{2}} \\
\varphi=-\arctan \left(B_{i}, A_{i}\right)
\end{gathered}
$$

i) repeat sequence of steps from (d) to (h), converting the model using the new values of $\mathrm{Ai}, \mathrm{Bi}$ and fi calculated from the previous iteration. On the basis of experiments, it was determined that the number of iterations should be accurately specified. The best results were achieved with six repetitions for the entire calculations cycle. This method doubles the number of significant digits in the parameter " $\mathrm{f}$ " with each iteration and converges very quickly.

The residuals of the fit and its error can be obtained from equations:

$$
\begin{gathered}
r[n]=x[n]-A_{i} \cos \left(2 \pi f_{i} t_{n}\right)-B_{i} \sin \left(2 \pi f_{i} t_{n}\right)-C_{i} \\
\varepsilon_{r m s}=\sqrt{\frac{1}{M} \sum_{n=1}^{M} r[n]^{2}}
\end{gathered}
$$

\section{Blade Tip Timing simulation}

All matching methods will be tested with the use of the data generated by the tiptiming measurement simulator. Data obtained from simulation represents a certain number of blade times to come before the face of the sensor. The resulting measurement points will provide a set of data used in the amplitude estimation in the matching method.

It is assumed that the blade rotates with frequency $\Omega=2 \pi \mathrm{f}_{\text {obr }}$ and passes in front of the sensor's face once per revolution. Next assumption is, that at the beginning of the simulation, for time $t=0$, the blade is in angular position $\varepsilon$. Hence, the time required, for not vibrating blade, to pass in front of the sensor face during the $\mathrm{k}$ number of revolutions, is:

$$
t_{c z u j n i k}=\frac{\varepsilon+\phi}{\Omega}+\frac{2 \pi k}{\Omega}
$$

where $\Omega$ is the rotational speed of the rotor for the specified measurement, $\varepsilon$ is the angle used to position the blade corresponding to the aisle of the first blade under first sensor and $\phi$ is the angle of the sensor with regard to the first one, which is the reference. 
Standard Sine Fitting Algorithms Applied to Blade Tip Timing Data

Zastosowanie standardowych algorytmów dopasowania funkcji sinus do danych...

On the basis of the above formula, times for the transitions of the blade under a given sensor, will be computed. In this case it is assumed that four sensors are arranged in positions:

$$
\begin{array}{ll}
\text { - sensor no. } 0 & \text { - } 0 \text { degrees, } \\
\text { - sensor no. } 1 & \text { - } 18 \text { degrees, } \\
\text { - sensor no. } 2 & \text { - } 33 \text { degrees, } \\
\text { - sensor no. } 3 & \text { - } 40 \text { degrees. }
\end{array}
$$

The appointed times of blade transitions are afterward stored in arrays t_czujnik_0, t_czujnik_1,t_czujnik_2, t_czujnik_3.

In the last step of creating a simulator, the whole received data should be put in a single array t_czujnik, so that, on the basis of transition times and blade vibration amplitudes, we can appoint temporary vibration amplitudes for the blade transitions under the sensor - A_czujnik matrix.

As a result, a simulation graph showing the variation of blade vibrations and its vibration amplitude at individual measurement points, corresponding to transitions under forefront of each of the four sensors, will be obtained.

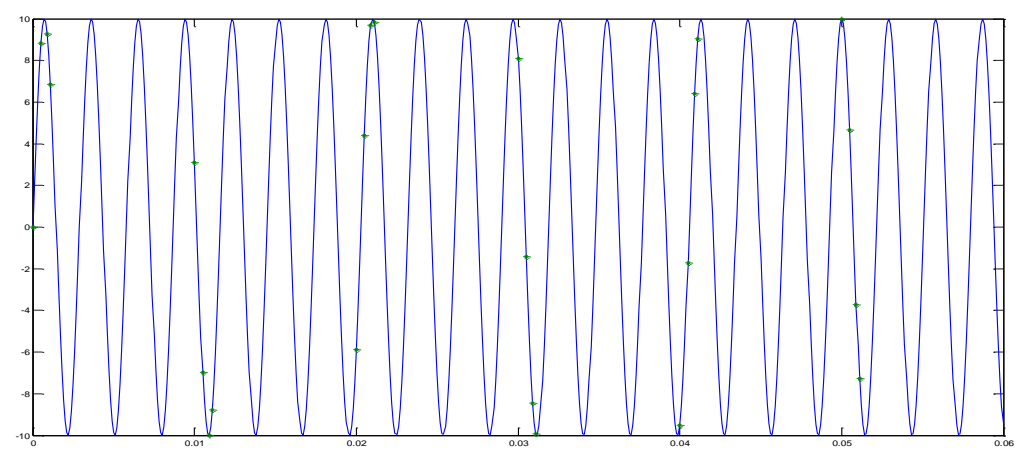

Fig. 1 Amplitude of blade vibrations

\section{Analysis of amplitude estimation algorithm using data from the tip-timing simulator}

Points generated by the tip-timing simulator described above were used to test the vibration amplitude estimation algorithm with use of the sine function matching method. The testing process was divided into two cases, respectively for three and four - parameters algorithms.

\section{Sine fitting using 3-parameter algorithm}

In the case of use of the 3-parameter fit algorithm using the least squares method, it was assumed that the frequency of wanted function is known. Amplitude estimation algorithm was tested for a number of situations:

a) analyzing the fitting process depending on the amount of generated points used in the matching algorithm, 
All tests were carried out with the revealed frequency of $345 \mathrm{~Hz}$. The amount of data used for the analysis is the parameter which was not changed. As a result, the following values were calculated: offset, phase shift, amplitude and number of iterations.

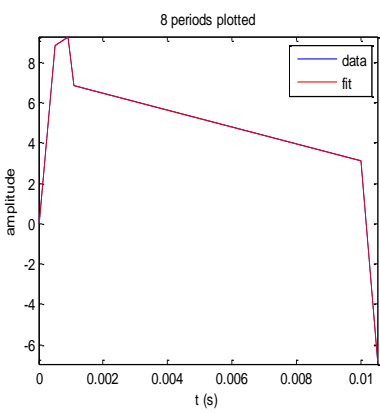

a)

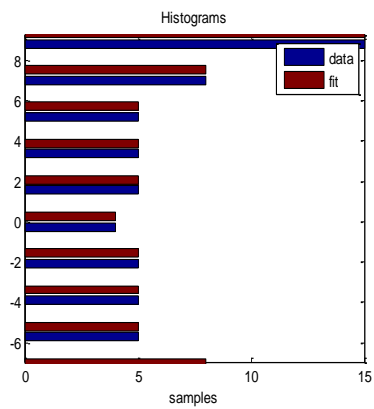

b)

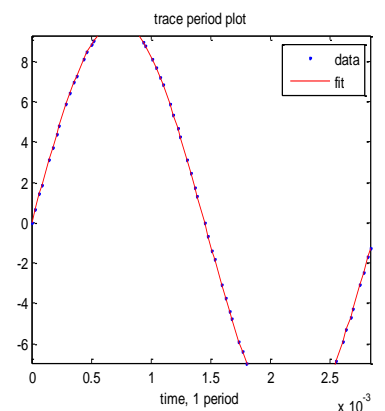

c)

Fig. 2 Example of a result of the sine function fitting

a) waveform generated on the basis of samples, $b$ ) histogram containing quantity of samples and their utilization in implementing the matching function,

c) the result of the matching function for one period

The results of the experiments showed that the number of points generated from the simulation that are used by matching algorithm using a sine function during seeking blade vibration function parameters, has no effect on number of iterations, value of the offset and amplitude in the case of 3 or 6 rotations. Phase shift in each case was corrupted. When using only eight data points for the two periods of the vibration signal, the number of calculations dropped to 1 iteration. However, the use of measurement points from one rotation, increases the number of iterations dramatically to 22 . At the same time, increasing the amount of point generated from simulation (to 20 revolutions) causes a noticeable increase in the value of the phase shift, without affecting other parameters.

b) analyzing the fitting process depending on the position of the sensors in the tiptiming simulation,

During carrying out a series of adjustments for different positions of the sensors, it was noted that their position does not affect the outcome of matches. The resulting parameters of the fitted sine functions are identical:

Tab. 1. Computed function parameters for different sensor locations

\begin{tabular}{|l|c|}
\hline Offset & 0 \\
\hline Amplitude & 10 \\
\hline Frequency & $345 \mathrm{~Hz}$ \\
\hline Phase shift & $-1.5708 \mathrm{rad}$ \\
\hline
\end{tabular}


Standard Sine Fitting Algorithms Applied to Blade Tip Timing Data

Zastosowanie standardowych algorytmów dopasowania funkcji sinus do danych...

c) analyzing the fitting process depending on the number of sensors in the tiptiming simulation.

Firstly, it was assumed that more sensors are deployed on the perimeter of the rotor body, including the availability of the places of possible assembly. Therefore, it was found that sensors can be arranged at $+/-60$ degrees from the reference sensor (0 degrees).

Further analysis of the matching process consisted in increasing the number of sensors. To the base amount ( 4 pieces) were added 4 more, which had a random distribution in the above mentioned range. The results, however, strongly suggest that the increased number of sensors does not affect the correctness of the matching algorithm and the resulting parameters of the sine function are identical to those for the base settings.

In the case of reducing the number of sensors - up to 1 , the same results were obtained as in the previous paragraphs. Conducted simulations show that the adjustment is impossible only in the case where the number of sampling points for one sensor is less than 2 .

\section{Sine fitting using 4-parameter algorithm}

In the second solution, the rough (+/- 20\%) value of frequency has to be given. The problem is non-linear, therefore a 4-parameter algorithm for least squares fitting must operate iteratively. For this method, the following experiments were performed:

a) increasing the number of data points:

- The best result was obtained for one rotation, for each start frequency,

- In case of 20 revolutions, the result was obtained when the given frequency was equal to expected one $(345 \mathrm{~Hz})$ and slightly higher in one of the cases $(370 \mathrm{~Hz})$

- In all cases the error of the phase estimation was in the range of $90^{\circ}-270^{\circ}$,

- Except one case, the amplitude was estimated with the accuracy of $+/-5 \%$

- A number close to $445 \mathrm{~Hz}$ was often received as a result of the frequency estimation instead of the expected value of $345 \mathrm{~Hz}$,

b) modifying the placement of tip-timing sensors:

- The estimation was performed in two cases: the first case using data for one rotation from four sensors, and the second - for six rotations and the same number of sensors.

- The best results were achieved for simulated sensors mounted only in the selected quarter of the circumference of the casing: $0^{\circ}-40^{\circ}$ or $300^{\circ}-340^{\circ}$. Sensors placed in two quarters at the same time strongly reduced the chance of getting the correct estimation result.

- More data, available in the case of 6-rotation fitting, did not increase the accuracy of estimation. Despite correctly placed sensors, the procedure was not able to identify any of the four parameters when the start frequency 
differed significantly from the expected value. The best results were achieved from sensors placed in the range of $300^{\circ}-340^{\circ}$.

c) changing the number of sensors:

- Attempt to fit the data for one rotation

Increasing the number of sensors above the primary 4 caused no noticeable change in the estimated parameters. The algorithm is unable to determine the frequency and other vibration parameters when the number of sensors is less than 4.

- Attempt to fit the data for 6 rotations

Higher number of points in 6-rotation dataset worsen operation of sine fit procedure. When number of sensors is increased, number of cases with the correct estimation results is reduced. However, reducing the number of sensors improved the convergence. If the sensor were placed in the position of 0,40 and 300, estimates of amplitude and frequency were found correctly for all tested initial frequencies. If more than one sensor was used, there was an expected error in determining the frequency but the amplitude and offset were estimated correctly.

\section{Summary}

The following observations can be made:

- The procedure is not optimized for non-uniform sampling and sensor placement.

- Phase shift is always estimated incorrectly, regardless of initial conditions, algorithm used, number of sensors and their placement, and the number of data points.

- In the case of 3-parameter estimation (with the frequency known a priori) the obtained amplitude and offset are independent of the rotations' number, number of sensors and their spacing.

- In the case of the 4-parameter estimation (when frequency is unknown):

- Probability of convergence is acceptable when the given frequency is very close to the expected value $( \pm 1 \%)$;

- Best results were obtained when multi-sensor data from one rotation was used;

- Sensors placed in one quarter of the circumference give better results than the ones distributed around the circle;

- The number of fitted data points should match (or be a multiply of) the number of sensors.

The project was financed by the Polish National Science Centre (NCN) under the decision DEC-2011/01/D/ST8/07612 
Standard Sine Fitting Algorithms Applied to Blade Tip Timing Data

Zastosowanie standardowych algorytmów dopasowania funkcji sinus do danych...

\section{References}

[1] Kollár István, Blair Jerome J. Improved determination of the best fitting sine wave in ADC testing. Instrumentation and Measurement, IEEE Transactions on, 2005, 54.5: 1978-1983.

[2] Bilau Tamás Zoltán et al. Four-parameter fitting of sine wave testing result: iteration and convergence. Computer Standards \& Interfaces, 2004, 26.1: 51-56.

[3] Handel Peter. Properties of the IEEE-STD-1057 four-parameter sine wave fit algorithm. Instrumentation and Measurement, IEEE Transactions on, 2000, 49.6: 1189-1193.

[4] IEEE Standard for Digitizing Waveform Recorders. IEEE Std 1057-2007 (Revision of IEEE 1057-1994). http://ieeexplore.ieee.org/

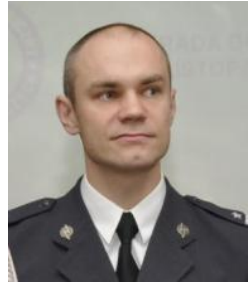

Radoslaw Przvsowa PhD. Eng. has been working as a engineer and scientist supporting machine maintenance since 2002, in the position of the Assistant Professor at the moment. He is also familiar with research management and commercialization and has remarkable programming skills, including obiect oriented programming, digital signal processing and data mining. He specializes in Blade Tiptiming, which is a non-contact vibration measurement method, involving processing of aliased displacement signals.

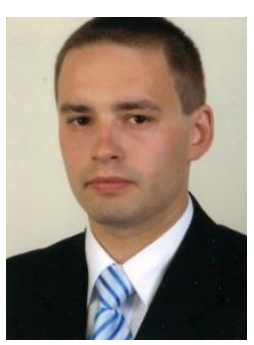

Krzvsztof Kazmierczak MSc. worked as an engineer (and later as a senior engineer) at the Air Force Institute of Technology for 6 years. He was responsible for designing, assembling and testing of prototype on-engine sensors, engine measurement and data recording systems. He currentlv works at the Institute of Fundamental Technological Research, Polish Academy of Sciences as a senior specialist and at the Military University of Technology as a teaching and research assistant. He specializes in embedded systems, avionics equipment and flight simulators. 